\title{
Experimental performance of an R134a automobile heat pump system coupled to the passenger compartment
}

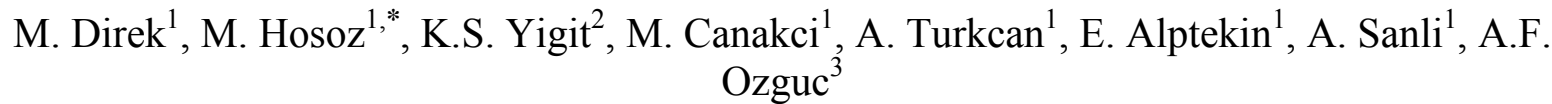 \\ ${ }^{1}$ Department of Mechanical Education, Kocaeli University, 41380 Kocaeli, Turkey \\ ${ }^{2}$ Department of Mechanical Engineering, Kocaeli University, 41040 Kocaeli, Turkey \\ ${ }^{3}$ Department of Mechanical Engineering, Istanbul Technical University, Istanbul, 34437, Turkey \\ * Corresponding author. Tel: +90 2623032279, Fax: +90 2623032203, E-mail: mhosoz@kocaeli.edu.tr
}

\begin{abstract}
This study presents experimental performance of an R134a automotive heat pump (AHP) system driven by a diesel engine and capable of utilizing the heat absorbed from the ambient air, engine coolant and exhaust gas. The experimental setup was developed from the components of the air conditioning system of a compact-size car, and tested by changing the engine speed, engine load and air temperatures entering the condenser and evaporator. The steady-state and transient performance characteristics of the AHP system for each heat source were evaluated by applying energy analysis to the system based on experimental data. Then, the performance parameters of the AHP system for three different heat sources were compared with each other and with those of the baseline heating system. The results show that the AHP system using engine coolant provides higher heating capacities and air temperatures at the register outlet in the first five minutes of the tests. However, the baseline heating system usually performs better than the AHP system when the steady-state is achieved. The AHP system caused an increase in the engine brake specific fuel consumption within the range of $4-54 \%$ depending on the engine load.
\end{abstract}

Keywords: Automotive heat pump, R134a, Refrigeration, Air conditioning, Automobile

\section{Introduction}

Passenger vehicles equipped with a water-cooled internal combustion engine usually utilize the engine waste heat in order to perform comfort heating of the passenger compartment under cold weather conditions. However, this coolant-based heating system cannot provide an appropriate thermal comfort in the passenger compartment until the coolant temperature rises to a certain value. This problem is more critical for the vehicles employing high-efficiency diesel engines due to the lack of sufficient waste heat within an acceptable duration of operation after the engine is started up. With the intention of obtaining thermal comfort rapidly, some vehicles utilize heaters using fuel or electricity. However, these systems have disadvantages such as high initial and operating cost, low efficiency and leading to air pollution as well as global warming. On the other hand, the problem of insufficient heating can be solved by adding some low cost components to the present air conditioning system of the vehicle to operate it as a heat pump. The automotive heat pump (AHP) system can heat the passenger compartment individually, or it can support the present heating system of the vehicle. In the literature, there are several investigations on the performance of AHP systems. Among these studies, Domitrovic et al. [1] simulated the steady-state cooling and heating operations of an automotive air conditioning (AAC) and heat pump system using R12 and $\mathrm{R} 134 \mathrm{a}$, and determined the change of the cooling and heating capacities, coefficient of performance $(C O P)$ and power consumption with ambient temperature at a fixed compressor speed. Hosoz and Direk [2] evaluated the performance of an air-to-air R134a AHP system, and compared its performance with the performance of the air conditioning system. Rongstam and Mingrino [3] evaluated the performance of an R134a AHP system using engine coolant as a heat source, and compared it with the performance of a coolant-based heating system at an ambient temperature of $-10^{\circ} \mathrm{C}$. Scherer et al. [4] reported an on-vehicle performance comparison of R152a and R134a AHP systems using engine coolant as a h eat source. 
Antonijevic and Heckt [5] developed and evaluated the performance an R134a AHP system, which was employed as a supplementary heating system. They carried out the tests at very low ambient temperatures and compared the performance of the AHP system with that of other supplemental heating systems.

In this study, an experimental AHP system capable of providing a conditioned air stream by utilizing the heat absorbed from the ambient air, engine coolant or exhaust gas was developed. In the experimental system, after passing through the indoor unit, the conditioned air stream was sent to the vehicle passenger compartment through a flexible air duct. In the experiments, the engine speed, engine load and air temperatures entering the condenser (indoor unit) and evaporator (outdoor unit) were controlled and concisely adjusted. The investigated performance parameters were the air temperature at the compartment front register outlet, mean air temperature in the passenger compartment, heating capacity, coefficient of performance and the increase in the brake specific fuel consumption (BSFC) of the engine caused by the operation of the AHP system.

\section{Methodology}

The experimental AHP system was usually made from the original components of an AAC system of a compact size car. As schematically shown in Fig. 1, it employs a seven-cylinder fixed-capacity swash-plate compressor, a p arallel-flow micro-channel outdoor coil, a laminated type indoor coil, two thermostatic expansion valves, a reversing valve to operate the system in reverse direction in heat pump operations, a brazed plate heat exchanger between the engine coolant and the refrigerant to serve as an evaporator and another plate heat exchanger to extract heat from the exhaust gas.

All lines in the refrigeration circuit of the system were made from copper tubing, and insulated by elastomeric material. The indoor and outdoor coils were inserted into separate air ducts of $1.0 \mathrm{~m}$ length. In order to provide the required air streams in the air ducts, a centrifugal fan and an axial fan were placed at the entrances of the indoor and outdoor air ducts, respectively. These ducts also contain electric heaters located upstream of the indoor and outdoor coils. The indoor and outdoor coil electric heaters can be controlled between 0-2 $\mathrm{kW}$ and $0-6 \mathrm{~kW}$, respectively, to provide the required air temperatures at the inlets of the related coils. The refrigeration circuit was charged with $1600 \mathrm{~g}$ of R134a. In order to gather data for the performance evaluation of the experimental AHP system, some mechanical measurements were conducted on it. The employed instruments and their locations are depicted in Fig. 1, and the characteristics of the instrumentation are reported in Table 1. 


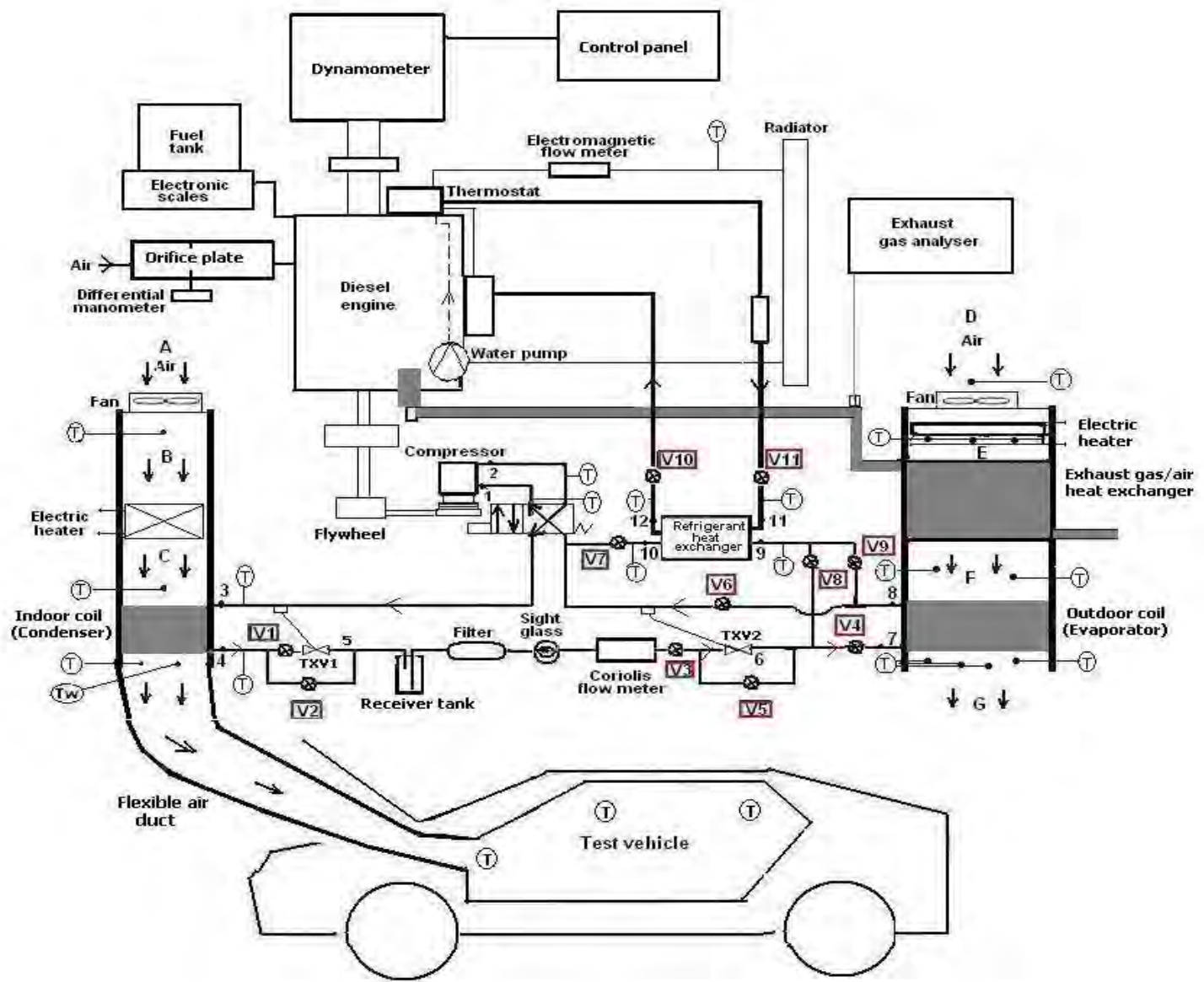

Fig. 1. Schematic illustration of the experimental AHP system and test vehicle (The arrows show the flow paths in the heat pump operations using ambient air and exhaust gas as a heat source).

Table 1. Characteristics of the instrumentation.

\begin{tabular}{cccc}
\hline Measured variable & Instrument & Range & Uncertainty \\
\hline Temperature & Type K thermocouple & $-50-500{ }^{\circ} \mathrm{C}$ & $\pm \% 0.3$ \\
Pressure & Pressure transmitter & $0-25 \mathrm{bar}$ & $\pm \% 0.2$ \\
Air speed & Anemometer & $0.1-15 \mathrm{~m} \mathrm{~s}^{-1}$ & $\pm \% 3$ \\
Refrigerant mass flow rate & Coriolis flow meter & $0-350 \mathrm{~kg} \mathrm{~h}^{-1}$ & $\pm \% 0.1$ \\
Compressor speed & Digital tachometer & $10-100000 \mathrm{rpm}$ & $\pm \% 2$ \\
Torque & Hydraulic dynamometer & $5-750 \mathrm{Nm}$ & $\pm \% 2$ \\
\hline
\end{tabular}

The refrigerant mass flow rate was measured by a Coriolis mass flow meter. The temperatures of the refrigerant and air at the inlet and outlet of each component were measured by K-type thermocouples. The refrigerant pressures at the inlet and outlet of the compressor were measured by both Bourdon gauges and pressure transmitters.

The AHP system was driven by a Fiat Doblo JTD diesel engine with a cylinder volume of $1900 \mathrm{cc}$ and a maximum power of $77 \mathrm{~kW}$ at $4000 \mathrm{rpm}$. The engine torque and speed were measured by means of a hydraulic dynamometer with a maximum measuring power of 100 $\mathrm{kW}$, a maximum torque of $750 \mathrm{Nm}$ and a maximum speed of $6000 \mathrm{rpm}$. The fuel consumption was measured using an electronic scale and a chronometer. Most of the measurement data were acquired through a data acquisition system and recorded on a computer.

The conditioned air stream discharged from the condenser duct was supplied to the passenger compartment of the test automobile Renault Safrane. The connection between the evaporator 
duct and the compartment was performed using an insulated flexible air duct. In order to measure the compartment temperatures, a thermocouple was located at the outlet of the front register, another one was suspended in the air close to the front left seat at the driver neck level, and the last one was suspended in the air close to the rear right seat at the passenger neck level.

Fig. 1 also illustrates the refrigerant flow paths in the experimental heat pump system for the cases of using ambient air or exhaust gas as a heat source. In order to perform the heat pump operation, the reversing valve is energized. Then, the reversing valve directs the high temperature superheated vapour refrigerant discharged from the compressor to the indoor coil. Afterwards, the refrigerant condensed in the indoor coil enters the outdoor unit (evaporator) through the thermostatic expansion valve (TXV2). The refrigerant evaporates by absorbing heat from the ambient air stream, which can be preheated by the exhaust gas/air heat exchanger in the heat pump operations using the exhaust gas as a heat source. Finally, the evaporated refrigerant is drawn by the compressor through the reversing valve.

In order to operate the experimental system as a heat pump using engine coolant as a heat source, the refrigerant is directed to the refrigerant/coolant heat exchanger after passing through the TXV2. In this case, the refrigerant absorbs heat from the engine coolant and has a high superheat at the exchanger outlet. In order to test the baseline heating system, the heater core is located downstream of the indoor coil and connected to the proper terminals of the engine thermostat. Further information on the experimental AHP system and its instrumentation can be found in references $[6,7]$.

The performance parameters of the experimental AHP system can be evaluated by applying the first law of thermodynamics to the system. Using this law for the indoor coil (condenser), the heating capacity of the experimental AHP system can be evaluated from

$$
\dot{Q}_{\text {cond }}=\dot{m}_{r}\left(h_{\text {cond , in }}-h_{\text {cond }, \text { out }}\right)
$$

where $\dot{m}_{r}$ is the refrigerant mass flow rate and $h$ is the enthalpy of the refrigerant.

Assuming that the compressor is adiabatic, the compressor power absorbed by the refrigerant can be obtained from

$$
\dot{W}_{\text {comp }}=\dot{m}_{r}\left(h_{\text {comp }, \text { out }}-h_{\text {comp }, \text { in }}\right)
$$

The energetic performance of the AHP system is found by evaluating its $C O P$, defined as the ratio between the heating capacity and compressor power, i.e.

$$
C O P=\frac{\dot{Q}_{\text {cond }}}{\dot{W}_{\text {comp }}}
$$

The power output from the engine, which is called the engine brake power, can be determined from the product of the engine torque and engine speed, i.e.

$$
\dot{W}_{\text {brake }}=T \frac{\pi n}{30}
$$


The brake specific fuel consumption of the engine can be evaluated from

$$
B S F C=3600 \frac{\dot{m}_{F}}{\dot{W}_{\text {brake }}}
$$

where $\dot{m}_{F}$ is the fuel consumption rate of the engine.

\section{Results}

In order to perform the tests, the diesel engine was operated at five different speeds, namely $850,1200,1550,1900$ and $2250 \mathrm{rpm}$. Because the diameters of the crankshaft and compressor pulleys are the same, the engine speed is equal to the compressor speed. The tests at $850 \mathrm{rpm}$ were performed at the dynamometer loads of both $5 \mathrm{Nm}$ (idling operation) and $60 \mathrm{Nm}$, while tests at other speeds were performed only at the dynamometer load of $60 \mathrm{Nm}$. In all tests, the air flow rate at the front register outlet was adjusted to its maximum $\left(0.403 \mathrm{~m}^{3} \mathrm{~s}^{-1}\right)$. In the tests using ambient air and exhaust gas as a heat source, the air flow rate passing through the outdoor coil was also adjusted to its maximum $\left(0.52 \mathrm{~m}^{3} \mathrm{~s}^{-1}\right)$. Before performing the tests, the air temperatures at the inlets of the indoor coil ( $\left.\mathrm{T}_{\text {ind coil, ain }}\right)$ and outdoor coil ( $\left.\mathrm{T}_{\text {outd coil, ain }}\right)$ both were fixed to $5{ }^{\circ} \mathrm{C}$. Meanwhile, the relative humidity of the air stream entering the outdoor coil was between 50 and $70 \%$. After these adjustments, the diesel engine was started up and the engine speed along with dynamometer load was rapidly adjusted to the required values. Using data acquired in the test operations, the steady-state performance of the AHP system was evaluated from the Eqs. (1-5), while the air temperature at the outlet of the front register and the mean air temperature in the compartment were considered as the parameters showing the transient behaviour of the system.

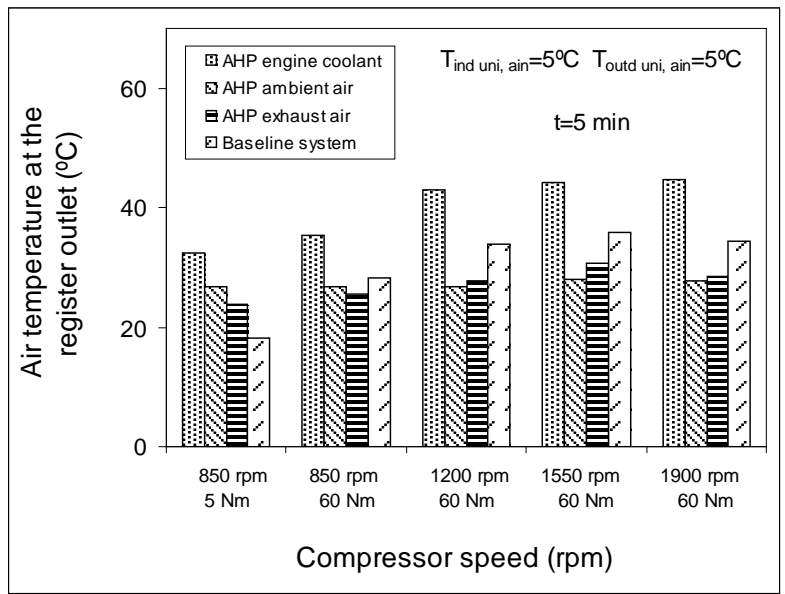

(a)

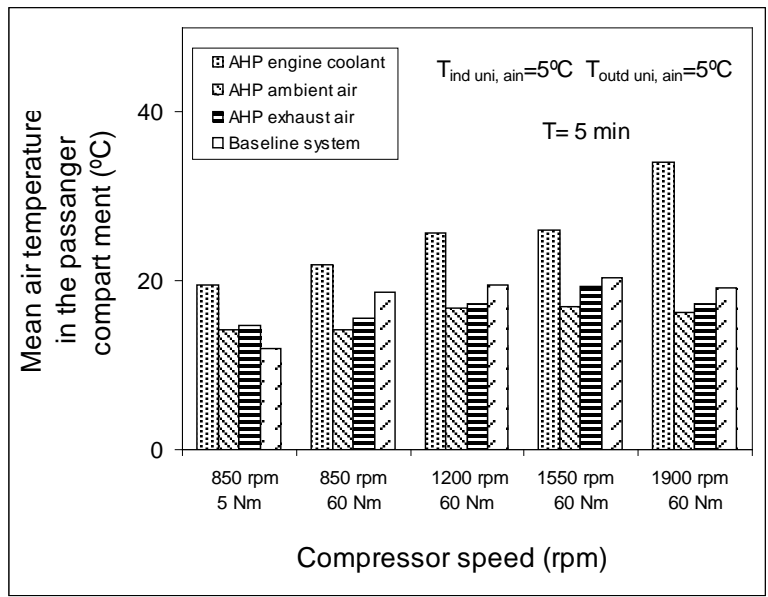

(b)

Fig. 2. The change of the air temperature at the compartment front register outlet (a); the change of the mean air temperature in the compartment (b) (both temperatures were recorded at the end of fiveminute operation period).

Fig. 2 (a) shows the comparison of the fifth minute air temperatures measured at the front register outlet of the vehicle for the AHP systems and baseline heating system for different compressor speeds and dynamometer loads. It can be seen that the AHP system using engine coolant has higher air temperatures at the front register outlet compared with the AHP systems using ambient air and exhaust gas as well as with the baseline heating system. As the engine coolant temperatures increases, the evaporating temperature also increases, thus yielding higher condensing temperatures and conditioned air temperatures. It is seen that in 
the heat pump operations, the air temperature at the front register outlet rises immediately after the compressor is started up. At $850 \mathrm{rpm}$ speed and $5 \mathrm{Nm}$ load conditions, the AHP system using engine coolant provides a fifth minute air temperature at the front register outlet of $32^{\circ} \mathrm{C}$, while the AHP system using ambient air and exhaust gas yields 26 and $23^{\circ} \mathrm{C}$, respectively, and the baseline heating system provides only $18^{\circ} \mathrm{C}$, which is unacceptably low.

The air temperature at the front register outlet rises for all AHP systems when the engine speed and load are increased. In the AHP systems using engine coolant and exhaust gas, this increase is due to the elevated coolant and exhaust gas temperatures, respectively. As the engine speed increases, the refrigerant mass flow rate also increases, thus providing higher heat rejection in the condenser and higher air temperatures at the front register outlet for all AHP systems. Although the AHP system using engine coolant yields higher fifth minute conditioned air temperatures than the baseline heating system, the AHP systems using ambient air and exhaust gas cannot usually provide so high temperatures. Fig. 2 (b) demonstrates the changes of the fifth minute mean air temperatures in the passenger compartment as a function of compressor speed. When the engine speed and load are increased, the mean air temperature in the passenger compartment rises for all AHP systems and the baseline system. For the operations with the engine coolant, this increase is due to the elevated coolant temperature.

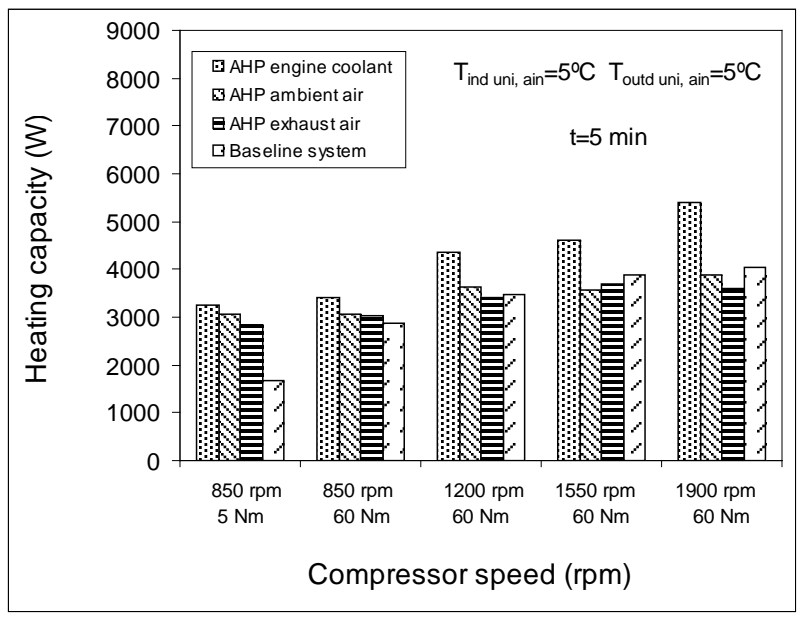

(a)

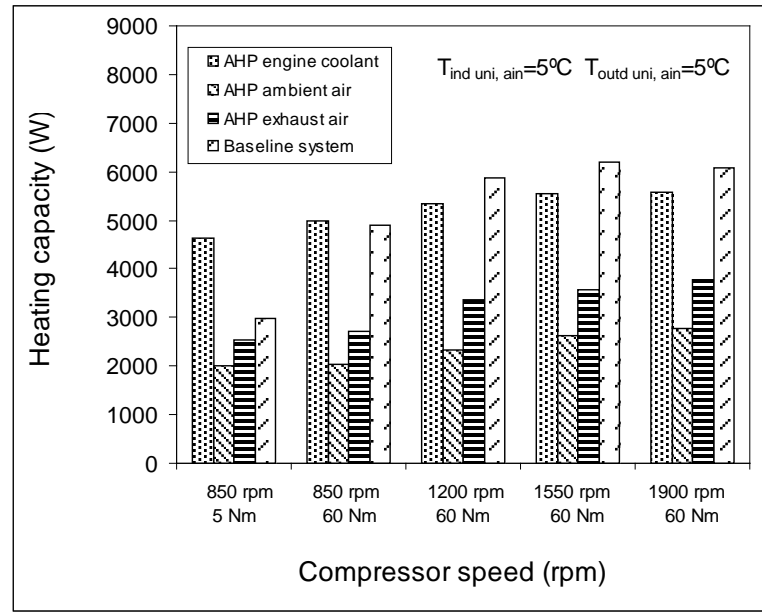

(b)

Fig. 3. The change of the heating capacity at the end of five-minute operation period (a); the steadystate heating capacity (b).

Fig. 3 (a) indicates the variations in the fifth minute heating capacity as a function of compressor speed. The heating capacity at the end of the five-minute operation period increases with the compressor speed at a constant engine load. At $60 \mathrm{Nm}$ load conditions, the coolant based AHP system has the highest fifth minute heating capacity at all engine speeds, which is usually followed by other heat pump systems and baseline heating system. Fig. 3 (b) demonstrates that the steady-state heating capacities are usually higher than the fifth-minute ones. In the AHP system with the engine coolant, the refrigerant absorbs a greater amount of heat from the coolant heat exchanger, thereby providing considerably higher heating capacities compared with the AHP system with ambient air or exhaust gas. In the tests performed at $850 \mathrm{rpm}$ and $5 \mathrm{Nm}$, the coolant based AHP system has the highest steady-state heating capacity, which is followed by the baseline heating system, AHP system using exhaust gas and AHP using ambient air in descending order. However, as the compressor speed is increased, the heating capacity of the baseline heating system gets higher. 
Fig. 4(a) indicates the variations in the coefficient of performance of the experimental AHP system as a function of compressor speed based on steady-state data. It is seen that the COP for heating decreases by increasing the compressor speed since the compressor power increases faster than the heating capacity does with increasing compressor speed. The AHP system using engine coolant provides the highest COP compared with the AHP systems using ambient air and exhaust gas. Fig. 4 (b) shows the impact of the operation of AHP systems on the brake specific fuel consumption at different compressor speeds and engine loads. The $B S F C$ increase caused by the AHP operations is very low when the engine speed and load are at high values because most of the power provided by the engine is applied to the dynamometer at these conditions. On the other hand, most of the power provided by the engine is used by the compressor of the AHP system when the engine is operated at low speeds and loads. Therefore, the increase in the BSFC due to the operation of the AHP system ranges between $4 \%$ and $54 \%$ depending on the engine speed and load.

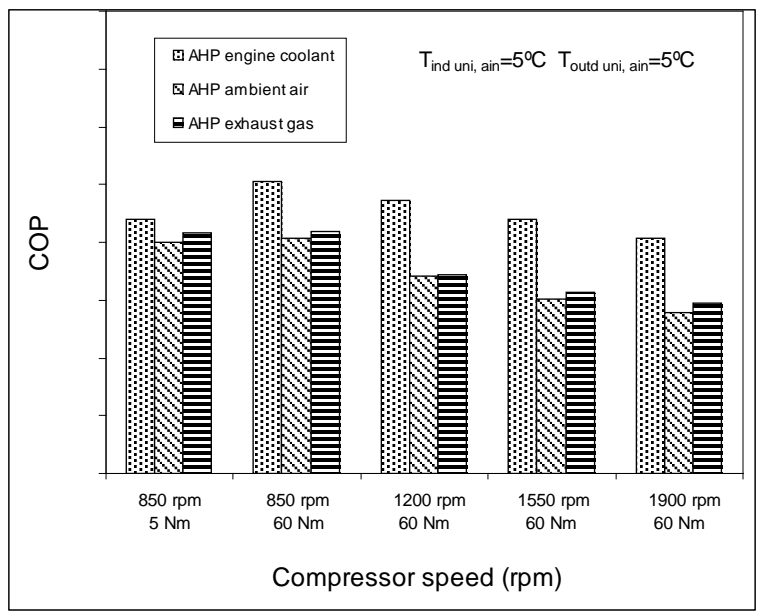

(a)

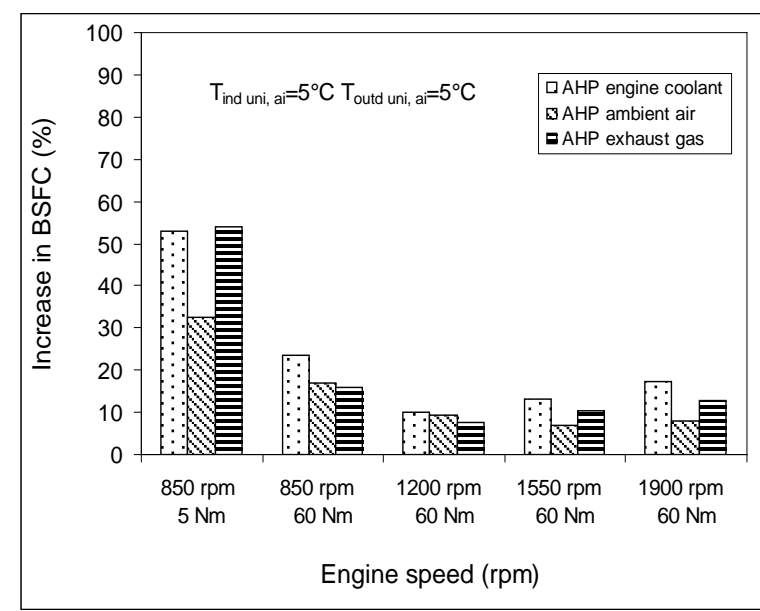

(b)

Fig. 4. The change of the COP (a); the increase in the brake specific fuel consumption caused by the operation of the AHP system (b).

\section{Discussion and conclusions}

Both transient and steady-state performance parameters of an experimental automotive heat pump system charged with R134a and using ambient air, exhaust gas and engine coolant as a heat source have been evaluated. The AHP system was coupled to the passenger compartment of a test vehicle by means of a flexible air duct in order to supply the conditioned air stream to the compartment. The performance of the AHP system for each source was revealed by performing tests at various compressor speeds and engine loads. The performance parameters of the AHP system for each heat source were compared with those of the system using other heat sources and with those of the baseline heating system. Based on experimental data, the heating capacity, coefficient of performance, air temperature at the front register outlet, mean air temperature in the compartment of the test vehicle and the increase in the BSFC caused by the operation of the AHP system were presented as a $\mathrm{f}$ unction compressor speed. The following conclusions can be drawn from this investigation:

- When the engine is operated at idling conditions ( $\mathrm{n}=850 \mathrm{rpm}$ and $\mathrm{T}=5 \mathrm{Nm}$ ), the AHP system using engine coolant provides the highest steady-state conditioned air temperatures and heating capacities compared with the AHP system using ambient air and exhaust gas and with the baseline heating system. 
- On increasing the engine torque and speed, the baseline heating system provides higher heating capacities after the steady-state has been achieved.

- The AHP system using any heat source yields higher conditioned air temperatures and heating capacities than the baseline heating system at the end of five-minute operation period when the engine is operated at the idling conditions.

- Only, the AHP system using engine coolant as a heat source provided a better fifth-minute heating capacity than the baseline heating system at speeds over $850 \mathrm{rpm}$ when the engine load is $60 \mathrm{Nm}$.

- The AHP system using the engine coolant yields the highest COPs, while the AHP system with ambient air results in the lowest ones.

- The AHP system causes an increase in the BSFC of the engine within the range of $4-54 \%$ depending on the engine speed and load.

Compared with the baseline heating system, when the engine speed and load are at low values, the use of all considered AHP systems at transient phase are advantageous in terms of heating capacity and conditioned air temperature. Because the AHP system using the engine coolant provides higher heating capacities than other alternatives, this system can heat the passenger compartment individually, or it can support the present heating system of the vehicle in expense of increased BSFC.

\section{Acknowledgement}

The authors would like to thank The Scientific and Technological Research Council of Turkey (TUBITAK) for supporting this study through a Research Project (Grant No. 108M132).

\section{References}

[1] E.R. Domitrovic, V.C. Mei, F.C. Chen, Simulation of an automotive heat pump. ASHRAE Transactions, 103, 1997, pp. 291-296.

[2] M. Hosoz, M. Direk, Performance evaluation of an integrated automotive air conditioning and heat pump system. Energy Conversion and Management, 47, 2006, pp. 545-559.

[3] J. Rongstam, F.A. Mingrino, A coolant-based automotive heat pump system, Vehicle Thermal Management Systems Conference (VTMS6) Proceedings, 2003, SAE Paper Code: C599/067/2003.

[4] L.P. Scherer, M. Ghodbane, J.A. Baker, P.S. Kadle, On-vehicle performance comparison of an R-152a and R-134a heat pump system, SAE Technical Papers, 2003, Paper code: 2003-01-0733.

[5] D. Antonijevic, R. Heckt, Heat pump supplemental heating system for motor vehicles, International Journal of Automobile Engineering: Part D, 218, 2004, pp. 1111-1115.

[6] M. Hosoz, M. Direk, K.S. Yigit, M. Canakci, E. Alptekin, A. Turkcan, Design and instrumentation of an automotive heat pump system using ambient air, engine coolant and exhaust gas as a heat source, 16th International Conference on Thermal Engineering and Thermogrammetry (THERMO), 2009, Budapest, Hungary.

[7] M. Hosoz, M. Direk, K.S. Yigit, M. Canakci, A. Turkcan, E. Alptekin, A. Sanli, A.F. Ozguc, Experimental performance of an automotive heat pump system for various heat sources, Congress on Automotive and Transport Engineering (CONAT 2010), 2010, Brasov, Romania, Paper code: CONAT 20104046. 